\title{
Correct use of non-indexed eGFR for drug dosing and renal drug-related problems at hospital admission
}

\author{
Sarah Seiberth ${ }^{1,2}$ (1) $\cdot$ Dominik Bauer $^{2} \cdot$ Ulf Schönermarck $^{3} \cdot$ Hanna Mannell $^{2} \cdot$ Christian Stief $^{4} \cdot$ Joerg Hasford $^{5}$. \\ Dorothea Strobach ${ }^{1,2}$ (D)
}

Received: 15 November 2019 / Accepted: 1 July 2020 / Published online: 10 July 2020

(C) The Author(s) 2020

\begin{abstract}
Purpose Two to seven percent of the German adult population has a renal impairment (RI) with an estimated glomerular filtration rate $(\mathrm{eGFR})<60 \mathrm{ml} / \mathrm{min} / 1.73 \mathrm{~m}^{2}$. This often remains unrecognized and adjustment of drug therapy is lacking. To determine renal function in clinical routine, the CKD-EPI equation is used to calculate an indexed eGFR $\left(\mathrm{ml} / \mathrm{min} / 1.73 \mathrm{~m}^{2}\right)$. For drug dosing, it has to be individualized to a non-indexed eGFR $(\mathrm{ml} / \mathrm{min})$ by the patient's body surface area. Here, we investigated the number of patients admitted to urological wards of a teaching hospital with RI between July and December 2016. Additionally, we correctly used the $\mathrm{eGFR}_{\text {non-indexed }}$ for drug and dosage adjustments and to analyse the use of renal risk drugs (RRD) and renal drug-related problems (rDRP).

Methods In a retrospective observational study, urological patients with pharmacist-led medication reconciliation at hospital

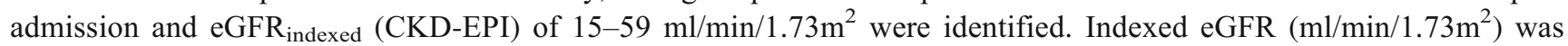
recalculated with body surface area to non-indexed eGFR $(\mathrm{ml} / \mathrm{min})$ for correct drug dosing. Medication at admission was reviewed for RRD and based on the eGFR non-indexed $_{\text {for }} \mathrm{PRP}$, e.g. inappropriate dose or contraindication.

Results Of 1320 screened patients, 270 (20.5\%) presented with an eGFR indexed $_{\text {of }} 15-59 \mathrm{ml} / \mathrm{min} / 1.73 \mathrm{~m}^{2}$. After readjustment, 203

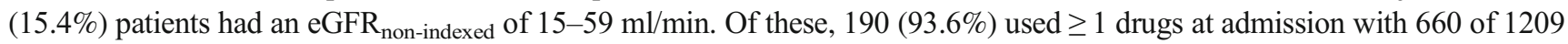
(54.7\%) drugs classified as RRD. At least one rDRP was identified in 115 (60.5\%) patients concerning 264 (21.8\%) drugs.

Conclusion Renal impairment is a common risk factor for medication safety in urologic patients admitted to a hospital. Considerable

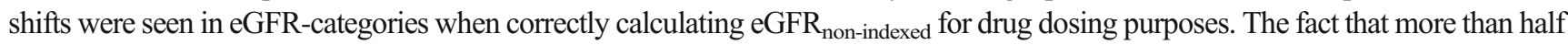
of the study patients showed rDRP at hospital admission underlines the need to consider this risk factor appropriately.
\end{abstract}

Keywords Renal impairment $\cdot$ Renal risk drugs $\cdot$ Renal drug-related problems $\cdot$ Non-indexed estimated glomerular filtration rate (eGFR)

Electronic supplementary material The online version of this article (https://doi.org/10.1007/s00228-020-02953-6) contains supplementary material, which is available to authorized users.

Sarah Seiberth

Sarah.Seiberth@med.uni-muenchen.de

Dominik Bauer

dominikbauer@mac.com

Ulf Schönermarck

Ulf.Schoenermarck@med.uni-muenchen.de

Hanna Mannell

Hanna.Mannell@med.uni-muenchen.de

Christian Stief

Christian.Stief@med.uni-muenchen.de

Joerg Hasford

has@ibe.med.uni-muenchen.de
Dorothea Strobach

Dorothea.Strobach@med.uni-muenchen.de

1 Hospital Pharmacy, University Hospital, LMU Munich, Marchioninistr. 15, 81377 Munich, Germany

2 Doctoral Program Clinical Pharmacy, University Hospital, LMU Munich, Marchioninistr. 15, 81377 Munich, Germany

3 Department of Medicine IV, University Hospital, LMU Munich, Marchioninistr. 15, 81377 Munich, Germany

4 Department of Urology, University Hospital, LMU Munich, Marchioninistr. 15, 81377 Munich, Germany

5 Institute of Medical Data Processing, Biometrics and Epidemiology (IBE), Faculty of Medicine, LMU Munich, Marchioninistr. 15, 81377 Munich, Germany 


\section{Introduction}

Renal impairment (RI), defined as an estimated glomerular filtration rate $(\mathrm{eGFR})<60 \mathrm{ml} / \mathrm{min} / 1.73 \mathrm{~m}^{2}$ [1], is a relevant health issue in Germany. About 2-7\% of the adult population are affected rising to $15-25 \%$ in patients aged over 60 years [1-3]. Unfortunately, in $72 \%$ of these patients, the RI remains unrecognized and only two-thirds of those, who are aware, are in medical care [2]. Adjustment of drug therapy is an important issue of patient safety in this patient group to avoid adverse drug reactions (ADR).

'Renal risk drugs' (RRD) either show altered pharmacokinetics or pharmacodynamics in RI or directly affect renal function [3, 4]. Dosage reduction and discontinuation of the drug or possibly harmful drug combinations have to be considered to avoid accumulation or nephrotoxicity, potentially leading to ADR [5, 6]. Additionally, drug activation (e.g. vitamin D) or pharmacological effectiveness (e.g. thiazides) may be influenced by RI [7, 8]. Inappropriate or missing adjustment of RRD to renal function may cause renal drugrelated problems (rDRP). Many rDRP are preventable if renal function is consequently considered. However, poor awareness of pre-existing RI and incorrect use of equations for renal function is still a problem. The use of potentially inappropriate drugs and dosages is common in patients with RI [9-12], increasing the rate of ADR [13-16].

In routine clinical practice, renal function is mostly determined using the endogenous filtration marker creatinine to calculate an eGFR or an estimated creatinine clearance (Fig. S1) [9].

To stage chronic kidney disease (CKD) for diagnosis, prognosis and treatment, the Kidney Disease Improving Global Outcomes Initiative (KDIGO) recommends the calculation of eGFR using the CKD Epidemiology Collaboration (CKD-EPI) equation and graduates eGFR in six categories $[1,17,18]$. CKD-EPI-equation estimates GFR $_{\text {indexed }}$ for a standard body surface area (BSA) of $1.73 \mathrm{~m}^{2}$ and can be used to compare renal function regardless of the individual's size and weight.

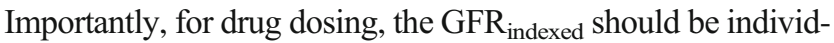
ualized for every patient to the units $\mathrm{ml} / \mathrm{min}$ by adjusting for the BSA calculated from actual weight and height $\left(\mathrm{eGFR}_{\text {non- }}\right.$ indexed) $[1,18,19]$. This is of special importance for patients whose BSA differs significantly from $1.73 \mathrm{~m}^{2}$ and for drugs with a narrow therapeutic index, yet since eGFR indexed $_{\text {is cal- }}$ culated automatically by many clinical laboratories, physicians tend to incorrectly use this parameter for drug dosing.

In comparison, the Cockcroft-Gault (CG) equation considers patients' weight and estimates a creatinine clearance in $\mathrm{ml} / \mathrm{min}$ [20]. It can directly be used for drug dosing and has been the standard for dose recommendations in most summary of product characteristics (SPC) in the last decades, but it has to be discussed which weight (e.g. total, ideal, adjusted or lean body weight) to use [21-24].
In addition to $\mathrm{CKD}$, acute kidney injury (AKI) has to be considered when drugs are prescribed. This is especially important in urologic patients, who often present with urinary flow obstructions at hospital admission. This may be transitory, but still overdosage and inappropriate drug selection are of immediate concern. Estimating renal function in AKI is challenging since creatinine is not in a steady-state [1].

With hospital admission, the physician on ward becomes responsible for a patient's drug therapy. The ambulant medications are generally continued during hospital stay. Therefore, dosing errors that have been introduced in ambulant care may be continued during the hospital stay and cause ADR, if not identified and corrected at the time of hospital admission. In our hospital, a pharmacist-led medication reconciliation is supporting this process. Since RI often remains unrecognized in outpatients, screening for decreased eGFR and $\mathrm{rDRP}$ at this transition of care is important.

To our knowledge, no data exist about the prevalence of impaired renal function in patients admitted to an urologic department of a tertiary teaching hospital. It is currently unknown, if and which RRD are taken by these patients and if rDRP exist. Additionally, the impact of using the eGFR non-

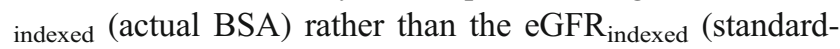
BSA) in clinical routine has not been addressed yet.

The objective of this study was to determine the number of patients admitted to urological wards presenting with RI and to evaluate how many of these patients changed eGFRcategories when referring to indexed vs. non-indexed eGFR, estimated with the CKD-EPI-equation. In addition, patients with eGFR non-indexed $15-59 \mathrm{ml} / \mathrm{min}$ were further analysed regarding RRD and rDRP concerning pre-existing drug therapy.

\section{Methods}

\section{Patients, setting and design}

We conducted a retrospective observational study of patients at the time of hospital admission to two urological wards of the University Hospital Munich, Germany, between July 2016 and December 2016. Patients were included if they were $\geq$ 18 years of age and received a pharmacist-led medication reconciliation at admission, generating a structured medication plan of all prescribed and over the counter drugs used. Readmissions were included, since the study was designed to represent a real-life setting and patient's renal function may change over time.

The following data were collected: age, gender, height, weight, $\mathrm{eGFR}_{\text {indexed }}$, drugs at admission including drugs ondemand and scheduled medications and comorbidities known to affect renal function. Body mass index (BMI), BSA (Mosteller equation) and $\mathrm{eGFR}_{\text {non-indexed }}$ were calculated $[18,25,26]$. 


\section{Ethical approval}

The study was conducted in accordance with the Declaration of Helsinki. Ethical approval was obtained from the ethics committee at Ludwig-Maximilians-University Munich, registration number 778-16.

\section{Data collection}

Data were collected from the hospital's electronical patient information system (SAP-i.s.h.med, Cerner Corporation, North Kansas City, USA) that includes medical reports, diagnoses and administrative documents. Drugs and dosages were extracted from the medication plans generated by a pharmacist at admission. Comorbidities were recorded either from SAPi.s.h.med or derived from the indication of drugs taken, e.g. statins for hypercholesterolemia.

\section{Renal impairment}

The eGFR indexed $_{\text {was automatically calculated by the clinical }}$ laboratory using the CKD-EPI-equation with standardized serum creatinine [27-29]. The pharmacist estimated BSA and readjusted the eGFR $R_{\text {indexed }}$ to $\mathrm{eGFR}_{\text {non-indexed }}$ for drug dosing recommendations by using the equation eGFR $_{\text {non-indexed }}=$ $\mathrm{eGFR}_{\text {indexed }} / 1.73 \mathrm{~m}^{2} \times$ BSA [18].

\section{Identification of 'renal risk drugs' and renal drug- related problems}

Furthermore, patients with eGFR $\mathrm{non}_{\text {-indexed }} 15-59 \mathrm{ml} / \mathrm{min}$ were identified and their medication at admission was screened for renal risk drugs (RRD) and renal drug-related problems (rDRP). RRD/rDRP were analysed for subgroups of eGFR-categories (15-29, 30-44 and 45-59 ml/min). The medications of patients with eGFR non-indexed $>60 \mathrm{ml} / \mathrm{min}$ usually do not need dose or drug adaption and patients with $\mathrm{eGFR}_{\text {non-indexed }}<15 \mathrm{ml} / \mathrm{min}$ are routinely under the care of a nephrologist; thus, they were not further analysed in this study.

The evaluation whether a drug was a RRD and whether the dosage was incorrect or contraindicated with the individual's $\mathrm{eGFR}_{\text {non-indexed }}$ was based on the information given in the German SPC or the drug information database AiDKlinik ${ }^{\circledR}$ that refers to the renal dose recommendation portal Dosing® (www.dosing.de). In case of discrepancies, an additional source was consulted [30].

\section{Classification of renal drug-related problems}

The renal drug-related problems (rDRP) were classified in consensus decision by three clinical pharmacists. rDRP were categorized with regard to 'PCNE Classification' and previous studies concerning rDRP (Fig. 1) [3, 4, 31]. All rDRP were classified as potential or manifest depending on the individual's eGFR ${ }_{\text {non-indexed. Manifest } r D R P}$ are present

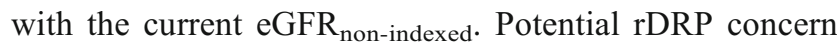

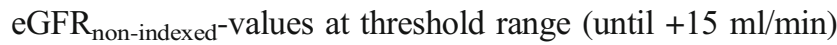
and action must be taken when renal function decreases further. The actual incidence of adverse clinical events resulting from rDRP was not investigated.

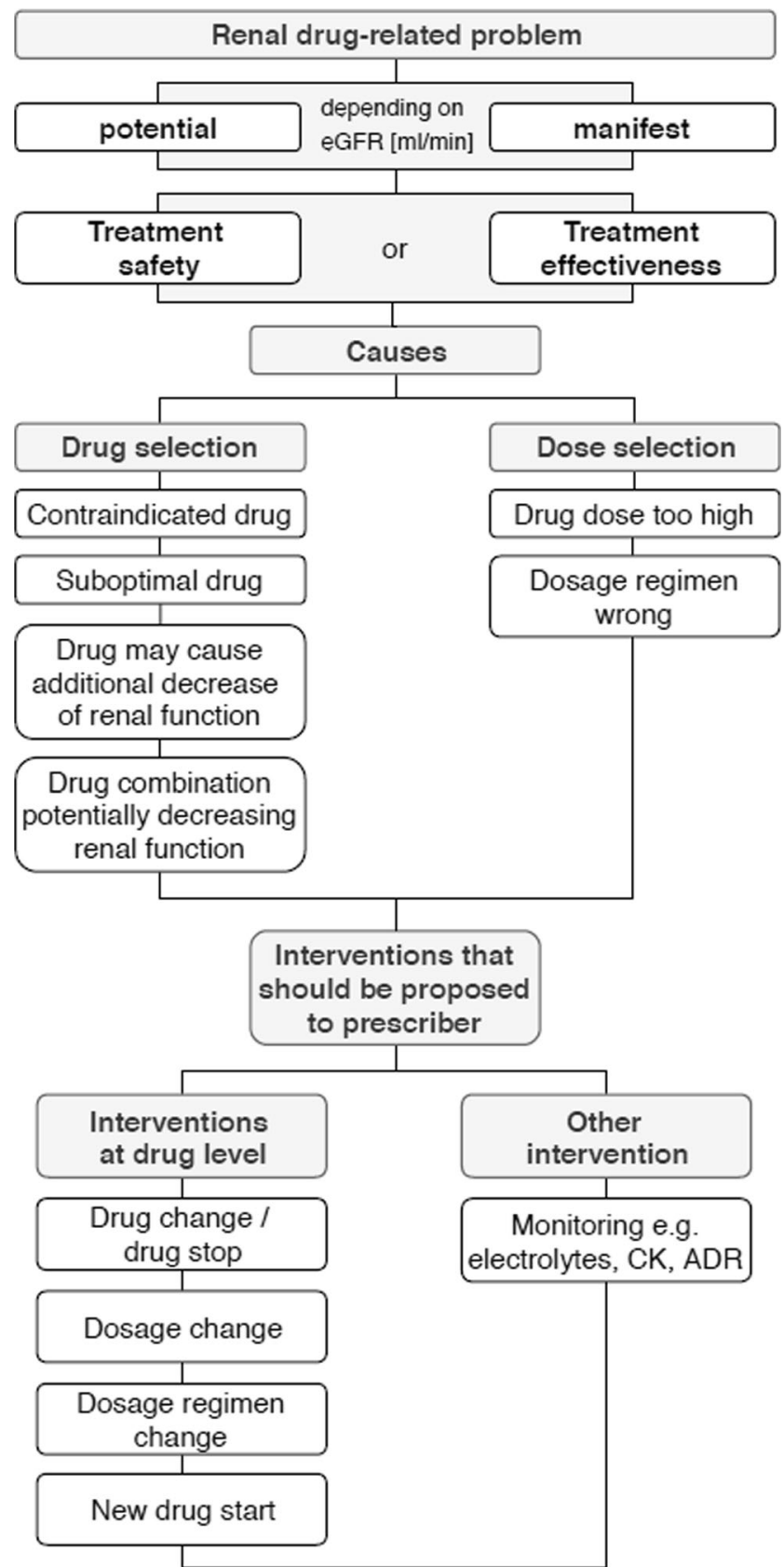

Fig. 1 Classification of potential/manifest renal drug-related problems depending on an individual's eGFR $(\mathrm{ml} / \mathrm{min})$. The renal drug-related problem (rDRP) of either treatment safety or treatment effectiveness is categorized in one main cause and more than one intervention might be necessary to solve rDRP. CK, creatine kinase; ADR, adverse drug reaction 
The rDRP concern either treatment safety or treatment effectiveness and are categorized in one main cause inducing the rDRP. One rDRP may lead to one or more interventions.

The suggested interventions were related to drug level and/ or need for 'monitoring'. Monitoring refers to control of serum blood levels (e.g. electrolytes, creatine kinase) or ADR. Monitoring of serum creatinine and eGFR was not included since it is mandatory in this patient population.

\section{Statistical analysis}

Data at admission were analysed using descriptive statistics. Qualitative variables are presented with their frequency distribution. Quantitative variables are expressed as the median and interquartile range (data without normal distribution). For comparison of the patient's characteristics concerning age and gender, Chi-square test was used for categorical variables (independent samples) and MannWhitney $U$ test for continuous variables (without normal distribution, independent samples). Statistical significance was accepted as $p<0.05$.

Statistical analyses and figures were performed with Microsoft Excel® 2016 (Seattle, WA, USA) and IBM SPSS Statistics ${ }^{\circledR}$ version 25.0 (Armonk, NY, USA).

\section{Results}

\section{Identification and categories of renal impairment: the impact of eGFR $_{\text {indexed }}$ versus eGFR non-indexed $_{\text {in }}$}

During the 6-month study period, 1341 patients were admitted. For 1320 (98\%) patients, pharmacist-led medication reconciliation was performed. The majority of all patients were male $(82.6 \%)$ and the median age 67 (18-94) years. Baseline characteristics of all patients are shown in Table 1.

As there is an uncertainty regarding which formula is routinely used for drug dosing purposes in clinical routine, we investigated the impact on the number of patients with renal impairment (RI) using eGFR indexed $_{\text {versus }}$ eGFR non-indexed $_{\text {- }}$ Two hundred seventy $(20.5 \%)$ patients had an eGFR $_{\text {indexed }}$ of $15-59 \mathrm{ml} / \mathrm{min} / 1.73 \mathrm{~m}^{2}$ and $16(1.2 \%)$ patients presented with eGFR indexed $<15 \mathrm{ml} / \mathrm{min} / 1.73 \mathrm{~m}^{2}$. However, the median BSA for all patients was noticeably higher than $1.73 \mathrm{~m}^{2}$ (median $\left.1.97 \mathrm{~m}^{2}, 1.17-2.86\right)$. When taking the patients' actual BSA into account and recalculating to $\mathrm{eGFR}_{\text {non-indexed, }} 67$ $(5.1 \%)$ patients were no longer in the critical range of $15-$ $59 \mathrm{ml} / \mathrm{min}$ (Figs. 2 and 3).

The remaining $203(15.4 \%)$ patients in the critical

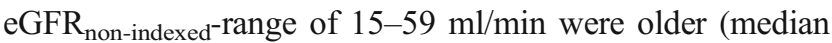
age 76 (30-94) years) in comparison with patients with eGFR $\geq 60 \mathrm{ml} / \mathrm{min}$ and significantly more often presented with comorbidities such as arterial hypertension, cardiovascular disease or hyercholesterolemia. There was no significant difference in the occurrence of prostatic hyperthrophy $(p=0.98)$, diabetes mellitus type $2(p=0.32)$ and urinary flow obstructions $(p=0.08)$.

Comparing male and female patients with $\mathrm{eGFR}_{\text {non-indexed }}$ $15-59 \mathrm{ml} / \mathrm{min}$, male patients presented with higher BMI and BSA, but no significant difference in age $(p=0.31)$, number of drugs $(p=0.62)$, and eGFR non-indexed $(p=0.69)$ was found. The comorbidities differed regarding hyperuricemia and cardiovascular diseases.

Comparing patients aged $<65$ and $\geq 65$ years, eGFR ${ }_{\text {non- }}$ indexed did not significantly differ $(p=0.88)$, while older patients took more drugs $(p<0.05)$.

\section{RRD and rDRP in patients with eGFR non-indexed $^{15-}$ $59 \mathrm{ml} / \mathrm{min}$}

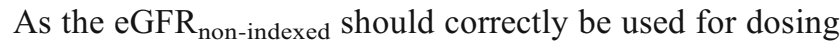
drugs, we next deciphered the occurrence of RRD and

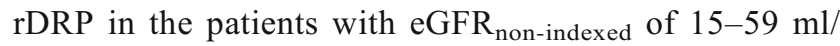
min. One hundred ninety $(93.6 \%)$ of the 203 patients took one or more drugs at admission (Table 2). In total, 1209 drugs were documented for these patients with a median number of $6(1-18)$ drugs per patient. Out of these, 660 (54.7\%) were identified as RRD with a median of $3(0-$ 11) RRD per patient. The 1209 drugs taken represented 218 different substances according to the Anatomical Therapeutic Chemical (ATC) classification system with $113(51.8 \%)$ matching the criteria of RRD.

Of the 660 RRD, 264 RRD led to rDRP concerning 76 different substances. This represents $21.8 \%$ of all medications and $40.0 \%$ of the RRD. One hundred fifteen patients of $190(60.5 \%)$ had rDRP already at hospital admission. The 260 documented rDRP represented a median number of 2 (0-10) rDRP per patient (Table 2). In two cases, the rDRP was a 'drug combination potentially decreasing renal function' triggered by three drugs. Thus, the number of $\operatorname{RRD}(n=264)$ is higher than the number of $\operatorname{rDRP}(n=$ 260).

\section{Detailed analysis of rDRP}

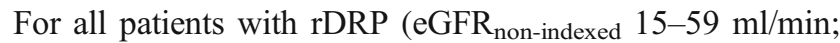
$n=115)$, more manifest $(58.5 \%)$ than potential $(41.5 \%)$ rDRP were found (Fig. 4). Enoxaparin and colecalciferol, followed by ramipril, spironolactone, hydrochlorothiazide, simvastatin and metformin are the drugs most often associated with rDRP (Fig. S2). The most frequent intervention for manifest rDRP would have been 'monitoring' and 'dosage change', and for potential rDRP 'dosage change' and 'drug change/drug stop'. 
Table 1 Baseline characteristics of all patients with pharmacist-led medication reconciliation, and for the $\mathrm{GFR}_{\text {non-indexed }}$-category subgroups. Data are quoted as the median (interquartile range) or $n$ (\%)

\begin{tabular}{|c|c|c|c|c|}
\hline eGFR categories $(\mathrm{ml} / \mathrm{min})$ & Overall & $<15$ & $15-59$ & $\geq 60$ \\
\hline No. of patients (n) & $1320^{*}$ & 15 & 203 & 1102 \\
\hline Males & $82.6 \%$ & $66.7 \%$ & $73.4 \%$ & $84.5 \%$ \\
\hline Age (years) & $67(18-94)$ & $72(33-93)$ & $76(30-94)$ & $66(18-94)$ \\
\hline $18-39$ & $7.5 \%$ & $46.7 \%$ & $0.5 \%$ & $8.8 \%$ \\
\hline $40-59$ & $21.4 \%$ & $20.0 \%$ & $7.4 \%$ & $24.0 \%$ \\
\hline $60-64$ & $12.5 \%$ & $0.0 \%$ & $9.4 \%$ & $13.2 \%$ \\
\hline $65-74$ & $29.8 \%$ & $26.7 \%$ & $25.1 \%$ & $30.8 \%$ \\
\hline$\geq 75$ & $28.8 \%$ & $46.7 \%$ & $57.6 \%$ & $23.2 \%$ \\
\hline $\mathrm{eGFR}_{\text {non-indexed }}(\mathrm{ml} / \mathrm{min})$ & $94(9-213)$ & $11(9-14)$ & $45(15-59)$ & $100(60-213)$ \\
\hline Weight $(\mathrm{kg})$ & $80(32-161)$ & $72(45-104)$ & $74(35-127)$ & $81(32-161)$ \\
\hline Height $(\mathrm{cm})$ & $\begin{array}{l}175 \\
\quad(148-199)\end{array}$ & $\begin{array}{l}170 \\
\quad(156-183)\end{array}$ & $\begin{array}{l}171 \\
\quad(148-188)\end{array}$ & $\begin{array}{l}176 \\
\quad(150-199)\end{array}$ \\
\hline BMI $\left(\mathrm{kg} / \mathrm{m}^{2}\right)$ & $\begin{array}{l}25.8 \\
\quad(13.0-51.9)\end{array}$ & $\begin{array}{l}23.1 \\
\quad(17.4-37.3)\end{array}$ & $\begin{array}{l}24.6 \\
\quad(13.0-38.7)\end{array}$ & $\begin{array}{l}26.0 \\
\quad(13.7-51.9)\end{array}$ \\
\hline$<18,5$ & $2.2 \%$ & $14.3 \%$ & $3.0 \%$ & $1.8 \%$ \\
\hline $18.5-24.9$ & $38.8 \%$ & $57.1 \%$ & $50.5 \%$ & $36.4 \%$ \\
\hline $25-29.9$ & $39.8 \%$ & $14.3 \%$ & $33.2 \%$ & $41.4 \%$ \\
\hline$\geq 30$ & $19.2 \%$ & $14.3 \%$ & $13.4 \%$ & $20.3 \%$ \\
\hline $\mathrm{BSA}\left(\mathrm{m}^{2}\right)$ & $\begin{array}{l}1.97 \\
\quad(1.17-2.86)\end{array}$ & $\begin{array}{l}1.87 \\
\quad(1.40-2.20)\end{array}$ & $\begin{array}{l}1.88 \\
\quad(1.26-2.55)\end{array}$ & $\begin{array}{l}1.99 \\
\quad(1.17-2.86)\end{array}$ \\
\hline No. of drugs at admission (n) & $3(0-20)$ & $8(1-13)$ & $5(0-17)$ & $3(0-17)$ \\
\hline 0 & $17.7 \%$ & $0.0 \%$ & $6.4 \%$ & $20.0 \%$ \\
\hline 1 or 2 & $23.9 \%$ & $6.7 \%$ & $17.2 \%$ & $25.4 \%$ \\
\hline 3 or 4 & $18.5 \%$ & $6.7 \%$ & $22.2 \%$ & $18.0 \%$ \\
\hline 5 or 6 & $14.8 \%$ & $26.7 \%$ & $12.8 \%$ & $15.1 \%$ \\
\hline 7 or 8 & $11.7 \%$ & $13.3 \%$ & $13.8 \%$ & $11.3 \%$ \\
\hline 9 or 10 & $7.0 \%$ & $20.0 \%$ & $14.8 \%$ & $5.4 \%$ \\
\hline$>10$ & $6.4 \%$ & $26.7 \%$ & $12.8 \%$ & $4.9 \%$ \\
\hline Comorbidities & $n(\%)$ & $n(\%)$ & $n(\%)$ & $n(\%)$ \\
\hline Arterial Hypertension & $655(49.6)$ & $13(86.7)$ & $140(69.0)$ & $502(45.6)$ \\
\hline Diabetes mellitus type 2 & $192(14.5)$ & $3(20.0)$ & $34(16.7)$ & $155(14.1)$ \\
\hline Hypercholesterolemia & $317(24.0)$ & $7(46.7)$ & $62(30.5)$ & $248(22.5)$ \\
\hline Cardiovascular disease & $114(8.6)$ & $3(20.0)$ & $33(16.3)$ & $78(7.1)$ \\
\hline Heart failure & $38(2.9)$ & $2(13.3)$ & $18(8.9)$ & $18(1.6)$ \\
\hline Pulmonary disease & $94(7.1)$ & $1(6.7)$ & $21(10.3)$ & $72(6.5)$ \\
\hline Hyperuricemia & $132(10.0)$ & $4(26.7)$ & $35(17.2)$ & $93(8.4)$ \\
\hline Prostatic hypertrophy & $317(29.1 * *)$ & $3(30.0 * *)$ & $49(32.9 * *)$ & $265\left(28.5^{* *}\right)$ \\
\hline $\begin{array}{l}\text { Outflow problems or obstruction of } \\
\text { urinary tract }\end{array}$ & $203(15.4)$ & $6(40.0)$ & $39(19.2)$ & $158(14.3)$ \\
\hline Hydronephrosis & $250(18.9)$ & $8(53.3)$ & $87(42.9)$ & $155(14.1)$ \\
\hline Kidney transplant & $6(0.5)$ & $1(6.7)$ & $2(1.0)$ & $3(0.3)$ \\
\hline
\end{tabular}

$* 222(16.8 \%)$ readmissions $* *$ referring to males

\section{Discussion}

In this study, for the first time, the prevalence and the nature of RRD and rDRP were assessed in patients presenting with RI at admission to urological wards in a tertiary teaching hospital.
Of note, we found that over half of the drugs taken at admission are RRD with $40.0 \%$ of these leading to rDRP. The use of indexed versus non-indexed eGFR has a noticeable impact on the determination of renal function, in turn influencing drug dosing and thus patient safety. 
Fig. 2 Patient flow of all patients admitted to two urological wards during 6 months
Fig. 3 Distribution of patients with eGFR indexed $_{\text {and }} \mathrm{GFR}_{\text {non- }}$ indexed according to eGFR-categories $(n=1320)$
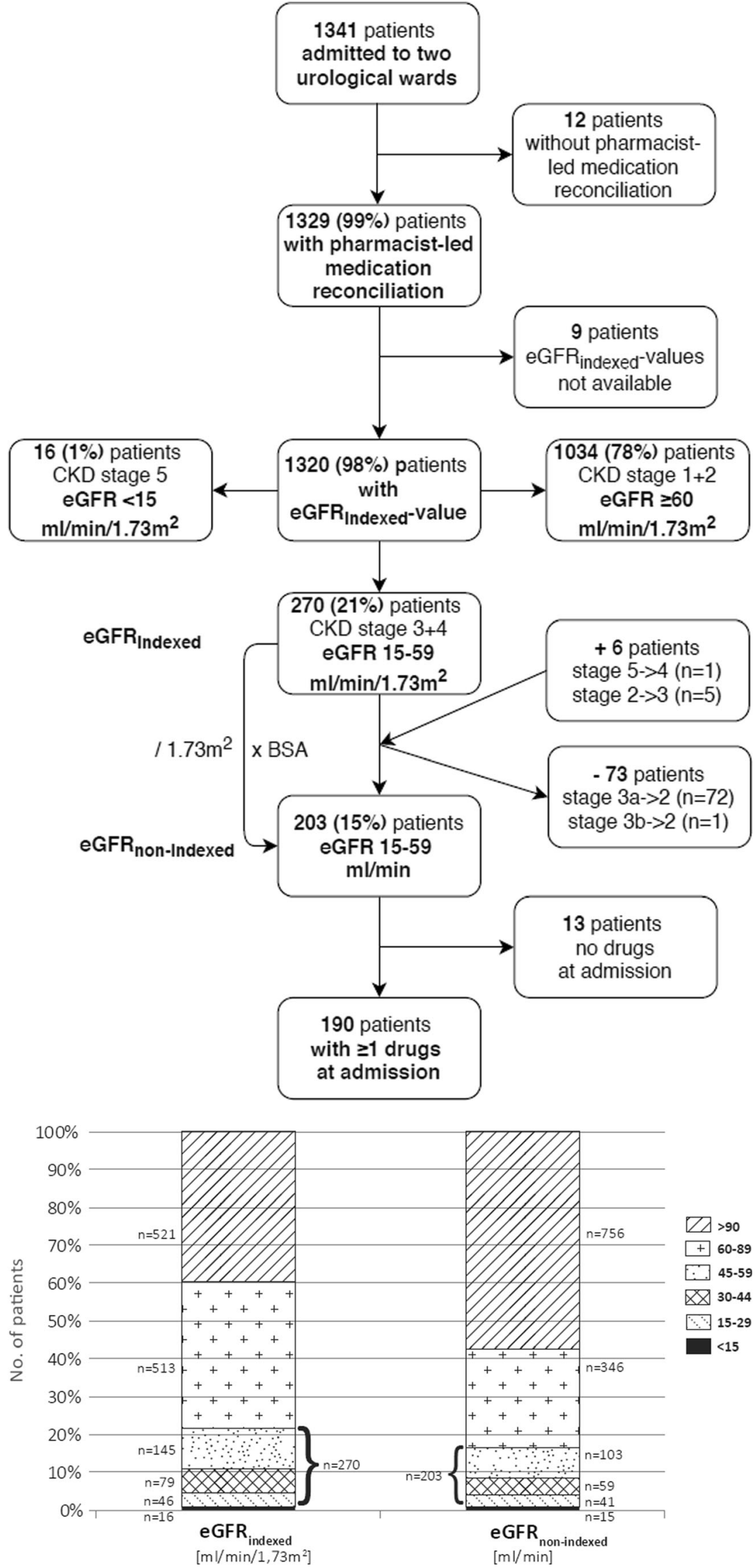
Table 2 Renal risk drugs (RRD) and renal drug-related problems (rDRP) in patients with eGFR non-indexed $_{15-59} \mathrm{ml} / \mathrm{min}$ and $\geq 1 \mathrm{drug}(n=190)$. Data are quoted as the median (interquartile range) or $n(\%)$

\begin{tabular}{|c|c|c|c|c|c|}
\hline \multirow[b]{2}{*}{$\mathrm{eGFR}_{\text {non-indexed }}(\mathrm{ml} / \mathrm{min})$} & & \multirow[b]{2}{*}{ Overall 15-59 } & \multicolumn{3}{|c|}{ eGFR categories } \\
\hline & & & $15-29$ & $30-44$ & $45-59$ \\
\hline No. of patients & $n$ & 190 & 39 & 56 & 95 \\
\hline \multirow[t]{2}{*}{ Drugs at admission } & $n$ & 1209 & 278 & 361 & 570 \\
\hline & median (range) & $6(1-18)$ & $6(1-18)$ & $6(1-17)$ & $5(1-14)$ \\
\hline Renal Risk Drugs (RRD) & $n(\%)$ & $660(54.7)$ & $160(57.5)$ & $187(51.8)$ & $313(54.9)$ \\
\hline No. of RRD per patient & median (range) & $3(0-11)$ & $4(0-11)$ & $3(0-10)$ & $3(0-9)$ \\
\hline RRD with rDRP & $n(\%)$ & $264 *\left(21.8^{* *}\right)$ & $107 *(38.5 * *)$ & $85^{*}\left(23.5^{* *}\right)$ & $72 *\left(12.6^{* *}\right)$ \\
\hline Patients with rDRP & $n(\%)$ & $115(60.5)$ & $31(79.5)$ & $35(62.5)$ & $49(51.6)$ \\
\hline No. of rDRP per patient & median (range) & $2(0-10)$ & $2(0-10)$ & $2(0-7)$ & $1(0-4)$ \\
\hline No. of rDRP & $n$ & 260 & 105 & 85 & 70 \\
\hline Potential $^{\mathrm{a}}$ & $n(\%)$ & $108(41.5)$ & 14 (13.3) & $61(71.8)$ & $33(47.1)$ \\
\hline with only monitoring $^{\mathrm{b}}$ & $n(\%)$ & $10\left(9.3^{\#}\right)$ & $0(0.0)$ & $6\left(10.0^{\#}\right)$ & $4\left(12.1^{\#}\right)$ \\
\hline Manifest $^{c}$ & $n(\%)$ & $152(58.5)$ & $91(86.7)$ & $24(28.2)$ & $37(52.9)$ \\
\hline with only monitoring ${ }^{\mathrm{b}}$ & $n(\%)$ & $57\left(37.2^{\#}\right)$ & $26\left(28.6^{\#}\right)$ & $14\left(56.0^{\#}\right)$ & $17\left(45.9^{\#}\right)$ \\
\hline
\end{tabular}

*Drugs were counted separately, when there was a drug interaction potentially decreasing renal function (two or three drugs per interaction)

***ercentage value refers to drugs at admission

\#Percentage value refers to potential or manifest rDRP

a: eGFR must be monitored, if it decreases, action must be taken

b: Monitoring as only intervention: Serum blood value (e.g. electrolytes) or adverse drug reaction must be monitored

c: rDRP is currently present with the current eGFR

We found $21.7 \%$ of patients to have RI with an $\mathrm{eGFR}_{\text {indexed }}<$ $60 \mathrm{ml} / \mathrm{min} / 1.73 \mathrm{~m}^{2}$ at hospital admission. The number of affected patients was expected to be higher in urology, since urinary flow obstructions and prostatic hypertrophy are typical for patients admitted to urologic wards, but this is within the similar range reported by other studies for all hospitalized patients or patients admitted to internal medicine $[3,6]$. There was however no difference in the occurrence of prostatic hypertrophy or urinary flow obstructions in the different eGFR-subgroups. We could not distinguish the percentage of patients with AKI or CKD or a combination of both at hospital admission, since eGFR-values from the past were rarely available.

Screening for RI at hospital admission is especially important considering that up to $72 \%$ of non-hospitalized CKD patients are not aware of their kidney insufficiency [2] and RI is an established risk factor for DRP [32]. Regarding the adjustment of drug therapy to renal function, it is vital to understand which estimation of GFR or renal clearance to use. For the classification of severity of the disease, international guidelines mainly recommend the use of the CKD-EPI-equation standardized to BSA of $1.73 \mathrm{~m}^{2}$ [1]. For drug dosing purposes, a measurement for renal function in $\mathrm{ml} / \mathrm{min}$ (eGFR $\mathrm{enon}_{\text {-indexed }}$ or $\mathrm{eKreaCl}$ ) should be used [19]. Noteworthy, most patients in this study had a higher BSA (median $1.97 \mathrm{~m}^{2}$, range 1.17-2.86) than the standard BSA of $1.73 \mathrm{~m}^{2}$, which influences the calculation of eGFR $\mathrm{non}_{\text {-indexed- }}$ Indeed, we detected a considerable shift of patients between
eGFR-subgroups when readjusting for actual BSA, resulting in a distinct decrease in the number of patients to consider for drug therapy adjustment. In fact, obesity is a rising problem in the last years and has to be considered for the estimation of renal function and drug dosing. Recent reviews summarize that for drug dosing, $\mathrm{eGFR}_{\text {indexed }}$ underestimates renal function, and therefore, eGFR $_{\text {non-indexed }}$ should be used [22, 23]. Indeed, our data suggest that the patient's individual weight and height have to be increas-

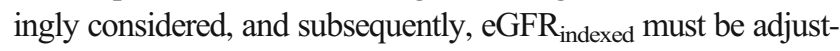
ed to patients' actual BSA for correct drug dosing. This recalculation to $\mathrm{eGFR}_{\text {non-indexed }}$ for drug dosing was not considered in comparable studies [3, 4]. Nevertheless, in our opinion, this is a crucial point to be stressed, since many practitioners are not aware of the differences between the calculations and their impact on determining renal function and thus drug dosing.

This study focused on patients with an eGFR non-indexed $_{15}$ $59 \mathrm{ml} / \mathrm{min}$ for two reasons. Firstly, adjustment of drug therapy is usually necessary for $\mathrm{GFR}_{\text {non-indexed }}<60 \mathrm{ml} / \mathrm{min}$ [30]. Secondly, whereas patients with $<15 \mathrm{ml} / \mathrm{min}$ are normally under supervision of a nephrologist, patients with $15-59 \mathrm{ml} /$ min are generally not and are therefore at increased risk for rDRP. Although we adjusted the eGFR indexed $_{\text {to }}$ the actual BSA (eGFR non-indexed $_{\text {, }}$, the number of patients displaying one or more rDRP (61\%) and the median number of rDRP/ patient was similar to studies from other medical departments using the eGFR indexed $[3,4]$. However, in our study, every 
a

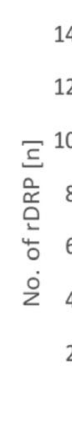

Potential

136

$140+\frac{136}{\square}$

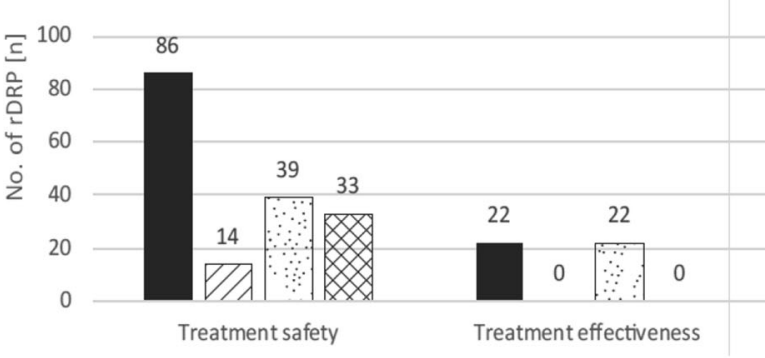

- Overall $\square$ eGFR $15-29 \mathrm{ml} / \mathrm{min}$

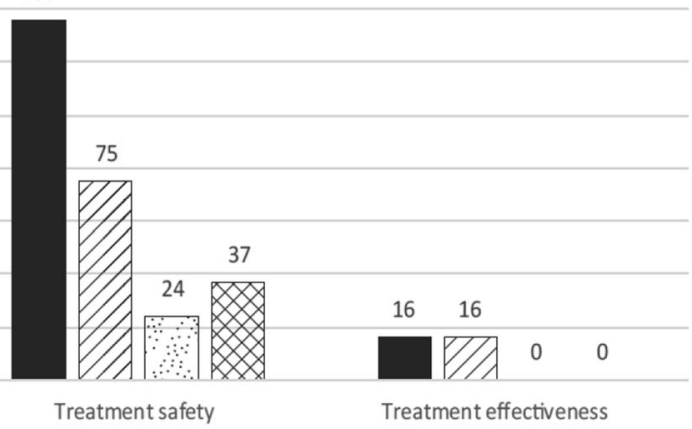

$\square$ eGFR $30-44 \mathrm{ml} / \mathrm{min}$

EGFR $45-59 \mathrm{~m} / \mathrm{min}$

b

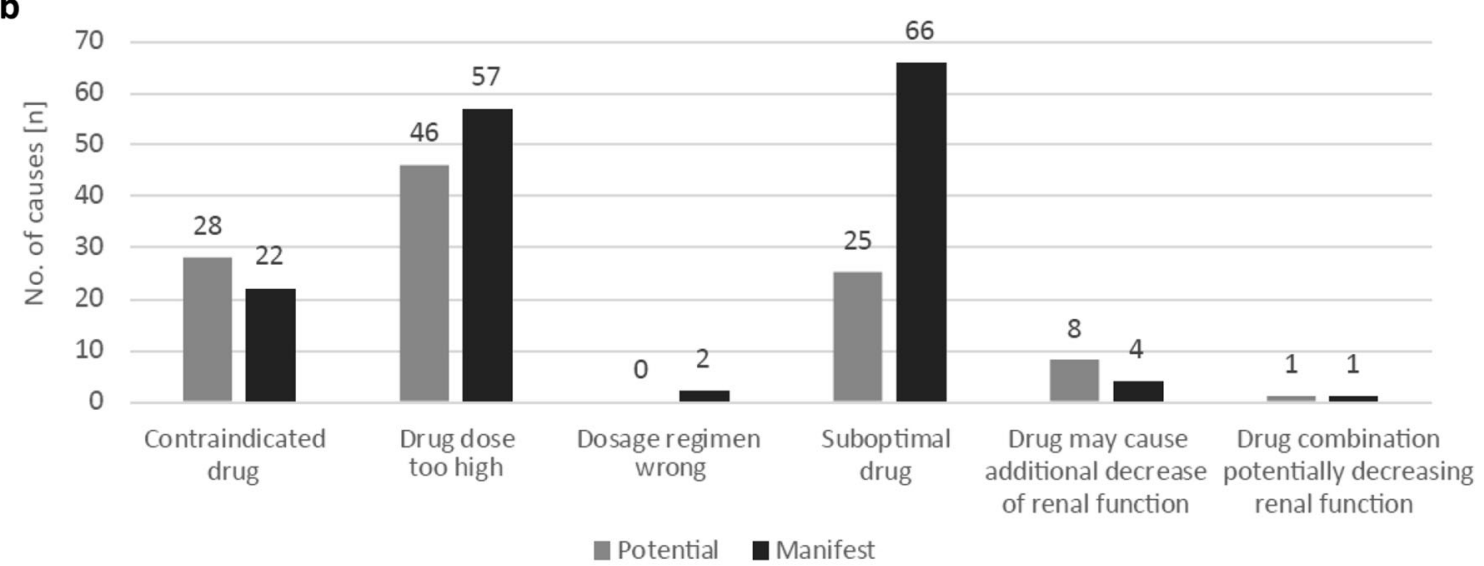

C

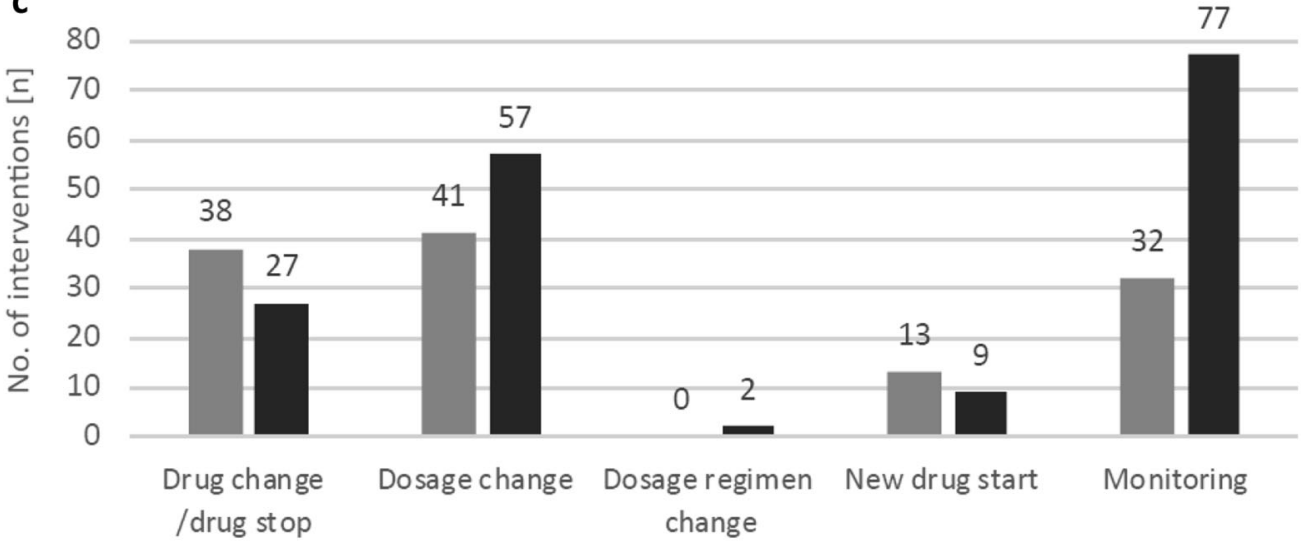

\section{Potential Manifest}

Fig. 4 Potential and manifest renal drug-related problems (rDRP) $(n=$ $260)$ in patients with eGFR non-indexed $_{\text {of }} 15-59 \mathrm{ml} / \mathrm{min}$ and $\geq 1$ drug $(n=$ 190). a Type of rDRP. b Causes of rDRP. c Interventions that should be

second drug was classified as RRD with about $40.0 \%$ of the RRD associated with rDRP, which is somewhat higher compared with other studies [3]. One reason for this might be that patients are admitted to an university hospital with more serious health problems, demanding consultation of specialists. This could lead to a higher number of drugs taken by patients proposed to prescriber to solve rDRP. Potential: eGFR must be monitored, if it decreases, action must be taken. Manifest: rDRP is currently present.

at a university hospital compared with non-university hospitals. However, we did not test this hypothesis. Manifest rDRP accounted with $58.5 \%$ for the majority of detected rDRP in our study. Use of suboptimal drugs, followed by overdosage and the presence of contraindications, were the causes in most cases. 
When distinguishing further in eGFR-subgroups, which represent common dosage frames, more manifest rDRP are seen in lower eGFR-ranges. Of note, more than half of manifest $\mathrm{rDRP}$ concerning treatment safety occurred in patients with an eGFR ${ }_{\text {non-indexed }} 15-29 \mathrm{ml} / \mathrm{min}$. The most frequently prescribed RRD associated with manifest rDRP in our patient population was low molecular weight heparins (LMWH; enoxaparin in this case). The unadjusted dosage of LMWH leads to a higher bleeding risk for patients with RI [30, 33]. Our data indicate that the awareness of correct prescribing of LMWH in patients with RI still seems to be problematic in the ambulant setting and therefore may also be a risk factor in the hospital setting.

Renal function can alter quickly in urologic patients after hospital admission, e.g. impairing in the perioperative period or improving after correction of urinary flow obstructions [34-36]. Therefore, we think it is important not only to focus on manifest rDRP but also to point out potential rDRP that may suddenly become relevant. The leading cause for potential rDRP was overdosage, followed by contraindication or the use of a suboptimal drug. This is in line with the findings of other studies where non-optimal dose and non-optimal drugs were the main causes for rDRP $[3,4]$. The most frequently prescribed drug associated with potential rDRP was vitamin D. Indeed, there are still uncertainties regarding the use (indication and type of vitamin D derivative) of vitamin D and its derivatives depending on renal function [7]. Physicians follow recommendations to prescribe vitamin D to patients with RI. As the main activation from colecalciferol to calcitriol takes place in the kidneys, a change of prescription to the activated form has to be considered from a certain stage of kidney disease on. In our experience, this is often neglected and there is a need of further guidance how to prescribe vitamin D derivatives depending on the severity of RI.

Additionally, it has to be kept in mind that some drugs are specifically used against their labeling e.g. hydrochlorothiazide in combination with loop diuretics with an eGFR < $30 \mathrm{ml} / \mathrm{min}$, and should not be classified as rDRP. Thus, it is important to use renal dosing references additionally to the SPC to determine RRD.

In non-hospitalized patients, inappropriate prescribing in RI was found in up to $80 \%$ and associated with more ADR, a longer hospital stay and a higher mortality risk [10, 12]. Thus, at hospital admission, screening for affected patients is of great importance as a proactive risk management. Physicians and pharmacists should work together to achieve safer drug prescribing [13]. The most significant reduction of inappropriate prescribing in patients with RI has indeed been observed when physicians received immediate feedback from pharmacists [12]. Prescription review followed by recommendations by a pharmacist has been shown to positively influence clinical outcome and even reduce costs of hospital stay [37]. In our study, for manifest and potential rDRP, the three most often recommended interventions to the physician on ward would have been monitoring, change of dosage and change or discontinuation of a drug.

Furthermore, it is important to recalculate the automatically reported eGFR $\mathrm{R}_{\text {indexed }}$ to the $\mathrm{GFR}_{\text {non-indexed }}$ before assessing the medication. In our experience, this recalculation is not usually performed by physicians on wards and the support of a pharmacist would be important. Moreover, the use of medication plans derived from medication reconciliation by a pharmacist at hospital admission, as in this study, can identify patients at risk. It has been shown that these plans are more complete and accurate compared with medication plans prepared by physicians $[38,39]$.

Some limitations of the study should be considered. This retrospective study focused on rDRP but did not assess possibly related adverse drug reactions, which should be included in future evaluations. Readmissions were included in our study to represent a real-life setting and because patient's renal function may change over time. However, this might have over- or underestimated the prevalence of RI in our study population. In addition, we assumed comorbidities from the indication of drugs taken by the patients because experiences from previous evaluations revealed that the documentation of diagnoses is often poor. This allows a more complete characterisation of the comorbidities in our study population. However, at the same time, due to drugs given without indication or due to diseases not treated adequately with drugs, errors may be included in our evaluation.

\section{Conclusion}

Our study provides novel evidence that urological patients with RI take a high number of RRD at hospital admission, leading to a substantial number of rDRP. This may be a risk factor for patient safety during the hospital stay. In addition, our analyses demonstrate considerable shifts of patients between eGFRcategories when recalculating eGFR from standard-BSA (indexed eGFR; $\mathrm{ml} / \mathrm{min} / 1.73 \mathrm{~m}^{2}$ ) to individual BSA (nonindexed eGFR; $\mathrm{ml} / \mathrm{min}$ ) for drug dosing purposes. This is an important point to avoid over- and underdosing or mistakes in contraindications that are frequently overlooked so far.

Future goals should be to develop a risk assessment to simplify the identification of the concerned patients during the pharmacist-led medication reconciliation at admission and to investigate the best way to inform physicians on ward about inappropriate drug use to ensure appropriate prescribing during the hospital stay.

Acknowledgements Open Access funding provided by Projekt DEAL. This work was supported by Stiftung Patient und Klinische Pharmazie, Munich, Germany. 
Authors' contributions Sarah Seiberth participated in the design of the study, was responsible for acquisition of data, classification of rDRP, performed the analysis and drafted the manuscript. Dominik Bauer participated as a clinical pharmacist in the classification of the rDRP and critically reviewed the manuscript. Ulf Schönermarck made substantial contributions to the conception of the study, interpretation of results and critically reviewed the manuscript. Hanna Mannell helped with statistical questions, analysis of the data and revision of the manuscript. Christian Stief critically revised the manuscript for important intellectual content. Joerg Hasford made substantial contributions to the conception and design of the study, including analyses, and manuscript preparation. Dorothea Strobach made substantial contributions to the conception and the design of the study, classified rDRP and was involved in result interpretation and manuscript preparation. All authors read and approved the final manuscript.

Funding information This work was supported by the interprofessional doctoral programme Clinical Pharmacy, Ludwig-Maximilians-University Munich, Germany and by the Stiftung Patient und Klinische Pharmazie, Munich, Germany.

Data availability The datasets used and/or analysed during the current study are available from the corresponding author on reasonable request.

\section{Compliance with ethical standards}

Competing interests The authors declare that they have no competing interests.

Ethical approval The study was conducted in accordance with the Declaration of Helsinki. Ethical approval was obtained from the ethics committee at Ludwig-Maximilians-University Munich, registration number 778-16.

Abbreviations ADR, adverse drug reactions; AKI, acute kidney injury; BMI, body mass index; BSA, body surface area; CK, creatine kinase; $\mathrm{CKD}$, chronic kidney disease; CKD-EPI, chronic kidney disease epidemiology collaboration; CG, Cockcroft-Gault; eGFR, estimated glomerular filtration rate; rDRP, renal drug-related problems; KDIGO, Kidney Disease Improving Global Outcomes Initiative; LMWH, low molecular weight heparins; RI, renal impairment; RRD, renal risk drugs; SPC, summary of product characteristics

Open Access This article is licensed under a Creative Commons Attribution 4.0 International License, which permits use, sharing, adaptation, distribution and reproduction in any medium or format, as long as you give appropriate credit to the original author(s) and the source, provide a link to the Creative Commons licence, and indicate if changes were made. The images or other third party material in this article are included in the article's Creative Commons licence, unless indicated otherwise in a credit line to the material. If material is not included in the article's Creative Commons licence and your intended use is not permitted by statutory regulation or exceeds the permitted use, you will need to obtain permission directly from the copyright holder. To view a copy of this licence, visit http://creativecommons.org/licenses/by/4.0/.

\section{References}

1. Kidney Disease: Improving Global Outcomes (KDIGO) CKD Work Group (2013) KDIGO 2012 clinical practice guideline for the evaluation and management of chronic kidney disease. Kidney Int Suppl 3:1-150

2. Girndt M, Trocchi P, Scheidt-Nave C, Markau S, Stang A (2016) The prevalence of renal failure. Results from the German Health Interview and Examination Survey for Adults, 2008-2011 (DEGS1). Deutsches Arzteblatt International 113 (6):85-91. doi: https://doi.org/10.3238/arztebl.2016.0085

3. Blix HS, Viktil KK, Moger TA, Reikvam A (2006) Use of renal risk drugs in hospitalized patients with impaired renal function-an underestimated problem? Nephrol Dial Transplant 21 (11):31643171. doi:https://doi.org/10.1093/ndt/gfl399

4. Holm H, Bjerke K, Holst L, Mathiesen L (2015) Use of renal risk drugs in patients with renal impairment. Int J Clin Pharm 37(6): 1136-1142. https://doi.org/10.1007/s11096-015-0175-3

5. Brater DC (2009) Drug dosing in patients with impaired renal function. Clin Pharmacol Ther 86(5):483-489. https://doi.org/10.1038/ clpt.2009.135

6. Hartmann B, Czock D, Keller F (2010) Drug therapy in patients with chronic renal failure. Deutsches Arzteblatt International 107(37):647-655

7. Cardoso MP, Pereira LAL (2018) Native vitamin D in pre-dialysis chronic kidney disease. Nefrologia : publicacion oficial de la Sociedad Espanola Nefrologia 39:18-28. https://doi.org/10.1016/j. nefro.2018.07.004

8. Jentzer JC, DeWald TA, Hernandez AF (2010) Combination of loop diuretics with thiazide-type diuretics in heart failure. $\mathrm{J} \mathrm{Am}$ Coll Cardiol 56(19):1527-1534. https://doi.org/10.1016/j.jacc. 2010.06.034

9. Munar MY, Singh H (2007) Drug dosing adjustments in patients with chronic kidney disease. Am Fam Physician 75(10):1487-1496

10. Dorks M, Allers K, Schmiemann G, Herget-Rosenthal S, Hoffmann F (2017) Inappropriate medication in non-hospitalized patients with renal insufficiency: a systematic review. J Am Geriatr Soc 65(4): 853-862. https://doi.org/10.1111/jgs.14809

11. Long CL, Raebel MA, Price DW, Magid DJ (2004) Compliance with dosing guidelines in patients with chronic kidney disease. Ann Pharmacother 38(5):853-858. https://doi.org/10.1345/aph.1D399

12. Tesfaye WH, Castelino RL, Wimmer BC, Zaidi STR (2017) Inappropriate prescribing in chronic kidney disease: a systematic review of prevalence, associated clinical outcomes and impact of interventions. Int J Clin Pract 71(7). https://doi.org/10.1111/ijcp. 12960

13. Hassan Y, Al-Ramahi R, Abd Aziz N, Ghazali R (2009) Drug use and dosing in chronic kidney disease. Ann Acad Med Singap 38(12):1095-1103

14. Hassan Y, Al-Ramahi RJ, Aziz NA, Ghazali R (2009) Impact of a renal drug dosing service on dose adjustment in hospitalized patients with chronic kidney disease. Ann Pharmacother 43(10): 1598-1605. https://doi.org/10.1345/aph.1M187

15. Hug BL, Witkowski DJ, Sox CM, Keohane CA, Seger DL, Yoon C, Matheny ME, Bates DW (2009) Occurrence of adverse, often preventable, events in community hospitals involving nephrotoxic drugs or those excreted by the kidney. Kidney Int 76(11):11921198. https://doi.org/10.1038/ki.2009.353

16. Breton G, Froissart M, Janus N, Launay-Vacher V, Berr C, Tzourio C, Helmer C, Stengel B (2011) Inappropriate drug use and mortality in community-dwelling elderly with impaired kidney function-the Three-City population-based study. Nephrol Dial Transplant 26(9): 2852-2859. https://doi.org/10.1093/ndt/gfq827

17. Inker LA, Astor BC, Fox CH, Isakova T, Lash JP, Peralta CA, Kurella Tamura M, Feldman HI (2014) KDOQI US commentary on the 2012 KDIGO clinical practice guideline for the evaluation and management of CKD. Am J Kidney Dis 63(5):713-735. https://doi.org/10.1053/j.ajkd.2014.01.416 
18. National Kidney Foundation (2014) Frequently asked questions about GFR estimates. USA. https://www.kidney.org/sites/default/ files/12-10-4004_FAQ-ABE.pdf

19. European Medicines Agency (2015) Guideline on the evaluation of the pharmacokinetics of medicinal products in patients with decreased renal function. https:/www.ema.europa.eu/en/documents/ scientific-guideline/guideline-evaluation-pharmacokineticsmedicinal-products-patients-decreased-renal-function en.pdf

20. Cockcroft DW, Gault MH (1976) Prediction of creatinine clearance from serum creatinine. Nephron 16(1):31-41

21. Morrish GA, Pai MP, Green B (2011) The effects of obesity on drug pharmacokinetics in humans. Expert Opin Drug Metab Toxicol 7(6):697-706. https://doi.org/10.1517/17425255.2011. 570331

22. Hart LA, Anderson GD (2018) Methods of estimating kidney function for drug dosing in special populations. Clin Pharmacokinet 57: 943-976. https://doi.org/10.1007/s40262-018-0628-7

23. Chang AR, Zafar W, Grams ME (2018) Kidney function in obesitychallenges in indexing and estimation. Adv Chronic Kidney Dis 25(1):31-40. https://doi.org/10.1053/j.ackd.2017.10.007

24. Hudson JQ, Nolin TD (2018) Pragmatic use of kidney function estimates for drug dosing: the tide is turning. Adv Chronic Kidney Dis 25(1):14-20. https://doi.org/10.1053/j.ackd.2017.10. 003

25. Mosteller RD (1987) Simplified calculation of body-surface area. $\mathrm{N}$ Engl J Med 317(17):1098. https://doi.org/10.1056/ nejm198710223171717

26. Fancher KM, Sacco AJ, Gwin RC, Gormley LK, Mitchell CB (2016) Comparison of two different formulas for body surface area in adults at extremes of height and weight. JS Oncol Pharm Pract 22(5):690-695. https://doi.org/10.1177/1078155215599669

27. Stevens LA, Schmid CH, Zhang YL, Coresh J, Manzi J, Landis R, Bakoush O, Contreras G, Genuth S, Klintmalm GB, Poggio E, Rossing P, Rule AD, Weir MR, Kusek J, Greene T, Levey AS (2010) Development and validation of GFR-estimating equations using diabetes, transplant and weight. Nephrol Dial Transplant 25(2):449-457. https://doi.org/10.1093/ndt/gfp510

28. Levey AS, Stevens LA, Schmid CH, Zhang YL, Castro AF, Feldman HI, Kusek JW, Eggers P, Van Lente F, Greene T (2009) A new equation to estimate glomerular filtration rate. Ann Intern Med 150(9):604-612

29. Stevens LA, Schmid CH, Greene T, Zhang YL, Beck GJ, Froissart M, Hamm LL, Lewis JB, Mauer M, Navis GJ, Steffes MW, Eggers PW, Coresh J, Levey AS (2010) Comparative performance of the CKD epidemiology collaboration (CKD-EPI) and the modification of diet in renal disease (MDRD) study equations for estimating GFR levels above $60 \mathrm{~mL} / \mathrm{min} / 1.73 \mathrm{~m} 2$. Am J Kidney Dis 56 (3): 486-495. doi:https://doi.org/10.1053/j.ajkd.2010.03.026

30. Ashley C, Dunleavy A (2017) The renal drug handbook: the ultimate prescribing guide for renal practitioners, vol 4th edition. Radcliffe Publishing, Abingdon, UK

31. Pharmaceutical Care Network Europe Foundation (PCNE) (2017) Classification for Drug related problems V8.02

32. Falconer N, Barras M, Cottrell N (2018) Systematic review of predictive risk models for adverse drug events in hospitalized patients. Br J Clin Pharmacol 84(5):846-864. https://doi.org/10.1111/bcp. 13514

33. Hoffmann P, Keller F (2012) Increased major bleeding risk in patients with kidney dysfunction receiving enoxaparin: a meta-analysis. Eur J Clin Pharmacol 68(5):757-765. https://doi.org/10.1007/ s00228-011-1149-6

34. Zarbock A, Koyner JL, Hoste EAJ, Kellum JA (2018) Update on perioperative acute kidney injury. Anesth Analg 127(5):1236 1245. https://doi.org/10.1213/ane.0000000000003741

35. Better OS, Arieff AI, Massry SG, Kleeman CR, Maxwell MH (1973) Studies on renal function after relief of complete unilateral ureteral obstruction of three months' duration in man. Am J Med 54(2):234-240. https://doi.org/10.1016/0002-9343(73)90228-3

36. Cheung CM, Ponnusamy A, Anderton JG (2008) Management of acute renal failure in the elderly patient: a clinician's guide. Drugs Aging 25(6):455-476. https://doi.org/10.2165/00002512200825060-00002

37. Jourdan JP, Muzard A, Goyer I, Ollivier Y, Oulkhouir Y, Henri P, Parienti JJ, Breuil C (2018) Impact of pharmacist interventions on clinical outcome and cost avoidance in a university teaching hospital. Int J Clin Pharm 40:1474-1481. https://doi.org/10.1007/ s11096-018-0733-6

38. Abdulghani KH, Aseeri MA, Mahmoud A, Abulezz R (2018) The impact of pharmacist-led medication reconciliation during admission at tertiary care hospital. Int J Clin Pharm 40(1):196-201. https://doi.org/10.1007/s1 1096-017-0568-6

39. Leguelinel-Blache G, Arnaud F, Bouvet S, Dubois F, Castelli C, Roux-Marson C, Ray V, Sotto A, Kinowski JM (2014) Impact of admission medication reconciliation performed by clinical pharmacists on medication safety. Eur J Int Med 25(9):808-814. https:// doi.org/10.1016/j.ejim.2014.09.012

Publisher's note Springer Nature remains neutral with regard to jurisdictional claims in published maps and institutional affiliations. 